\title{
ENGINEERING OF CHEMICAL COMPLEXITY
}




\title{
WORLD SCIENTIFIC LECTURE NOTES IN COMPLEX SYSTEMS
}

Editor-in-Chief: A.S. Mikhailov, Fritz Haber Institute, Berlin, Germany

B. Huberman, Hewlett-Packard, Palo Alto, USA

K. Kaneko, University of Tokyo, Japan

Ph. Maini, Oxford University, UK

Q. Ouyang, Peking University, China

\begin{abstract}
AIMS AND SCOPE
The aim of this new interdisciplinary series is to promote the exchange of information between scientists working in different fields, who are involved in the study of complex systems, and to foster education and training of young scientists entering this rapidly developing research area.

The scope of the series is broad and will include: Statistical physics of large nonequilibrium systems; problems of nonlinear pattern formation in chemistry; complex organization of intracellular processes and biochemical networks of a living cell; various aspects of cell-to-cell communication; behaviour of bacterial colonies; neural networks; functioning and organization of animal populations and large ecological systems; modeling complex social phenomena; applications of statistical mechanics to studies of economics and financial markets; multi-agent robotics and collective intelligence; the emergence and evolution of large-scale communication networks; general mathematical studies of complex cooperative behaviour in large systems.
\end{abstract}

Published

Vol. 1 Nonlinear Dynamics: From Lasers to Butterflies

Vol. 2 Emergence of Dynamical Order: Synchronization Phenomena in Complex Systems

Vol. 3 Networks of Interacting Machines

Vol. 4 Lecture Notes on Turbulence and Coherent Structures in Fluids, Plasmas and Nonlinear Media

Vol. 5 Analysis and Control of Complex Nonlinear Processes in Physics, Chemistry and Biology

Vol. 6 Frontiers in Turbulence and Coherent Structures

Vol. 7 Complex Population Dynamics: Nonlinear Modeling in Ecology, Epidemiology and Genetics

Vol. 8 Granular and Complex Materials

Vol. 9 Complex Physical, Biophysical and Econophysical Systems

Vol. 10 Handbook on Biological Networks

Vol. 11 Engineering of Chemical Complexity 
World Scientific Lecture Notes

in Complex Systems - Vol. 11

\section{editors}

\section{Alexander S Mikhailov Gerhard Ertl}

Fritz Haber Institute of the Max Planck Society, Germany

\section{ENGINEERING OF CHEMICAL COMPLEXITY}


Published by

World Scientific Publishing Co. Pte. Ltd.

5 Toh Tuck Link, Singapore 596224

USA office: 27 Warren Street, Suite 401-402, Hackensack, NJ 07601

UK office: 57 Shelton Street, Covent Garden, London WC2H 9HE

\section{British Library Cataloguing-in-Publication Data}

A catalogue record for this book is available from the British Library.

\section{World Scientific Lecture Notes in Complex Systems - Vol. 11 ENGINEERING OF CHEMICAL COMPLEXITY}

Copyright (c) 2013 by World Scientific Publishing Co. Pte. Ltd.

All rights reserved. This book, or parts thereof, may not be reproduced in any form or by any means, electronic or mechanical, including photocopying, recording or any information storage and retrieval system now known or to be invented, without written permission from the Publisher.

For photocopying of material in this volume, please pay a copying fee through the Copyright Clearance Center, Inc., 222 Rosewood Drive, Danvers, MA 01923, USA. In this case permission to photocopy is not required from the publisher.

ISBN 978-981-4390-45-3

Typeset by Stallion Press

Email: enquiries@stallionpress.com

Printed in Singapore. 


\section{PREFACE}

How to engineer chemical systems whose operation is self-organized? This question becomes topical in the light of an impressive progress in understanding of complex chemical systems of inorganic and biological origins. The gained knowledge makes it already possible to proceed to the next stage where not only the purposeful control of such natural systems, but also the attempts to design their synthetic counterparts can be made. The phenomenon of life, emerged as a product of a specific biological evolution, may thus be transferred to a broad range of artificial systems which are designed for particular applications. In the long perspective, this would revolutionize the technology, moving it from the present form, essentially based on the mechanistic concepts of the $19^{\text {th }}$ century, to the functional organization characteristic for living beings. Early indications of the approaching transition can be seen in the current research on the design of genetic networks, on the development of artificial or synthetic living cells, and on the construction and manipulation of single-molecule protein machines.

This book provides a survey of the current state of the art in the analysis, design and control of complex chemical systems. It is based on the plenary and selected invited talks given at the international conference "Engineering of Chemical Complexity" which had taken place in the summer of 2011 and was hosted by the newly established Berlin Center for Studies of Complex Chemical Systems. The book includes such topics as the manipulation and steering of single molecules and molecular motors, design of the systems based on active soft matter, control of collective dynamics and synchronization behavior, synthetic biology and the development of protocells.

While organizing the conference and preparing this publication, we have relied on the assistance by Ingeborg Reinhardt, Ulrike Christine Künkel and Rico Buchholz; we would like to express our sincere gratitude to all of them. We are pleased to acknowledge generous financial support provided for the conference from the German Research Foundation (DFG), from the Collaborative Research Center (SFB 910) "Control of Selforganizing Nonlinear Systems", the Training Research Group (GRK 1558) "Nonequilibrium Collective Dynamics in Condensed Matter and Biological Systems", and from the Solvay Company. 
This page intentionally left blank 


\section{CONTENTS}

Preface $\quad$ v

PART I INTRODUCTION 1

1. Analysis, Design and Control of Complex Chemical Systems 3 Alexander S. Mikhailov and Gerhard Ertl

\section{PART II SINGLE MOLECULES, NANOSCALE PHENOMENA AND ACTIVE PARTICLES}

2. Imaging and Manipulation of Single Molecules by Scanning Tunneling Microscopy

Leonhard Grill

3. Self-Organization at the Nanoscale in Far-FromEquilibrium Surface Reactions and Copolymerizations

Pierre Gaspard

4. Single Molecule and Collective Dynamics of Motor

Protein Coupled with Mechano-Sensitive Chemical Reaction

Mitsuhiro Iwaki, Lorenzo Marcucci, Yuichi Togashi

and Toshio Yanagida

5. Nanomotors Propelled by Chemical Reactions

Raymond Kapral

6. Biology of Nanobots

Wentao Duan, Ryan Pavlick and Ayusman Sen 


\section{PART III REACTION-DIFFUSION SYSTEMS} AND NONEQUILIBRIUM SOFT MATTER

7. Wave Phenomena in Reaction-Diffusion Systems

Oliver Steinbock and Harald Engel

8. Self-Oscillating Polymer Gels as Smart Materials

Ryo Yoshida

9. Stochastic Fluctuations and Spontaneous Symmetry

Breaking in the Chemotaxis Signaling System

of Dicyostelium Cells

Tatsuo Shibata

10. Mechanochemical Pattern Formation in the Polarization

of the One-Cell C. Elegans Embryo

Justin S. Bois and Stephan W. Grill

\section{PART IV OSCILLATIONS AND SYNCRONIZATION}

11. Synchronization of Electrochemical Oscillators

Mahesh Wickramasinghe and István Z. Kiss

12. Turbulence and Synchrony in Spatially Extended

Electrochemical Oscillators

Vladimir Garcia-Morales and Katharina Krischer

13. Quorum Sensing and Synchronization in Populations of Coupled Chemical Oscillators

Annette F. Taylor, Mark R. Tinsley and Kenneth Showalter

14. Collective Decision-Making and Oscillatory Behaviors in Cell Populations

Koichi Fujimoto and Satoshi Sawai 
15. Synchronization via Hydrodynamic Interactions

Franziska Kendelbacher and Holger Stark

\section{PART V EVOLUTION, SYNTHETIC BIOLOGY,} AND PROTOCELLS

16. Emergence and Selection of Biomodules: Steps in the Assembly of a Protocell

Susanna C. Manrubia and Carlos Briones

17. From Catalytic Reaction Networks to Protocells

Kunihiko Kaneko

18. Constructive Approach Towards Protocells

Tadashi Sugawara, Kensuke Kurihara and Kentaro Suzuki

19. Network Reverse Engineering Approach in Synthetic Biology

Haoqian Zhang, Ao Liu, Yuheng Lu, Ying Sheng,

Qianzhu Wu, Zhenzhen Yin, Yiwei Chen, Zairan Liu, Heng Pan and Qi Ouyang

Index 